\title{
MADELUNG'S DISEASE OF THE WRIST AND DYSCHONDROSTEOSIS
}

\author{
J. S. R. Golding, Kingston, Jamaica, and J. S. Blackburne, London, England
}

Twenty-six index patients with primary Madelung's deformity of the wrist were examined, as were sixty-five of their relatives. Standard radiographs were taken and measured to determine whether mesomelic dwarfism, a feature of dyschondrosteosis, was present. No case of mesomelia was found. No evidence of Madelung's deformity was found in the relatives of the index patients, who were all female. It is concluded that primary Madelung's deformity of the wrist is not an expression of dyschondrosteosis, that it is not inherited, and that it does not occur in the male. One index patient with dyschondrosteosis was examined. Eight of her relatives were similarly affected, and three of these were male. It is suggested that previously recorded male cases of Madelung's deformity of the wrist were expressions of dyschondrosteosis or of secondary deformity.

In 1878 Madelung described the necropsy appearance of the wrist of a girl aged twenty in a paper entitled "Spontaneous subluxation of the hand". Since that time many further cases have been reported. Anton, Reitz and Spiegel (1938) described a case and analysed 170 cases from the literature. They concluded that the condition was commoner in females in the ratio of four females to one male. the commonest cause of Madelung's deformity, and that the two conditions were in fact identical. However, Felman and Kirkpatrick (1969) studied the radiographs of seventeen patients with Madelung's deformity and concluded that only six of these represented dyschondrosteosis.

The purpose of the study reported in this paper was to determine whether primary Madelung's deformity is

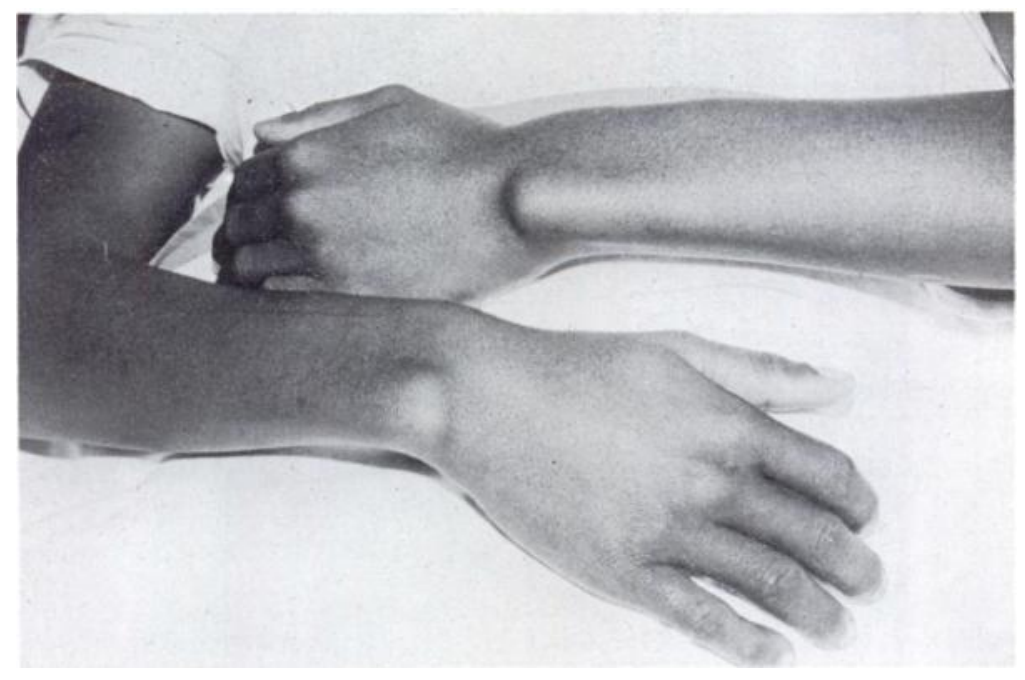

FIG. 1

Bilateral Madelung's deformity of the wrist.

In 1929 Léri and Weill had described a condition of hereditary dwarfism in which a wrist deformity, similar to that described by Madelung, was the most constant and obvious defect. The forearms and lower legs were short compared with the proximal and distal parts of the extremities-a condition known as mesomelia. They called the syndrome dyschondrosteosis. Herdman, Langer and Good (1966) believed that dyschondrosteosis was usually an expression of dyschondrosteosis, and if this is not so whether it is a heritable disorder or ever occurs in the male.

There is in clinical practice little problem in diagnosis. The clinical and radiographic features of the deformity are ulnar and dorsal curvature of the radius, decreased length of the radius, triangulation of the distal radial epiphysis, premature fusion of the ulnar half of the distal

Professor J. S. R. Golding, C.D., O.B.E., University Hospital of the West Indies, Kingston, Jamaica.

J. S. Blackburne, M.A., F.R.C.S., Royal National Orthopaedic Hospital, Brockley Hill, Stanmore, Middlesex HA7 4LP, England. 
radial growth plate, dorsal subluxation of the head of the ulna, and deformity of the proximal row of the carpus with the lunate as the apex of a triangle (Figs. 1 to 3 ).

\section{METHOD}

The index patients with Madelung's deformity and as many of their relatives as possible were examined. Radiographs of the upper and lower extremities were taken by
(Fig. 4) and twenty relatives of the patient in Case M. M. (Fig. 5). In three of the seven families four generations were studied, and in the others three.

We were unable to detect evidence of Madelung's deformity in any relative of the index patients. None of the lower limbs measured showed mesomelia. We therefore conclude that there is no evidence that primary Madelung's deformity of the wrist is inherited and that Madelung's deformity is not a minor expression of dys-

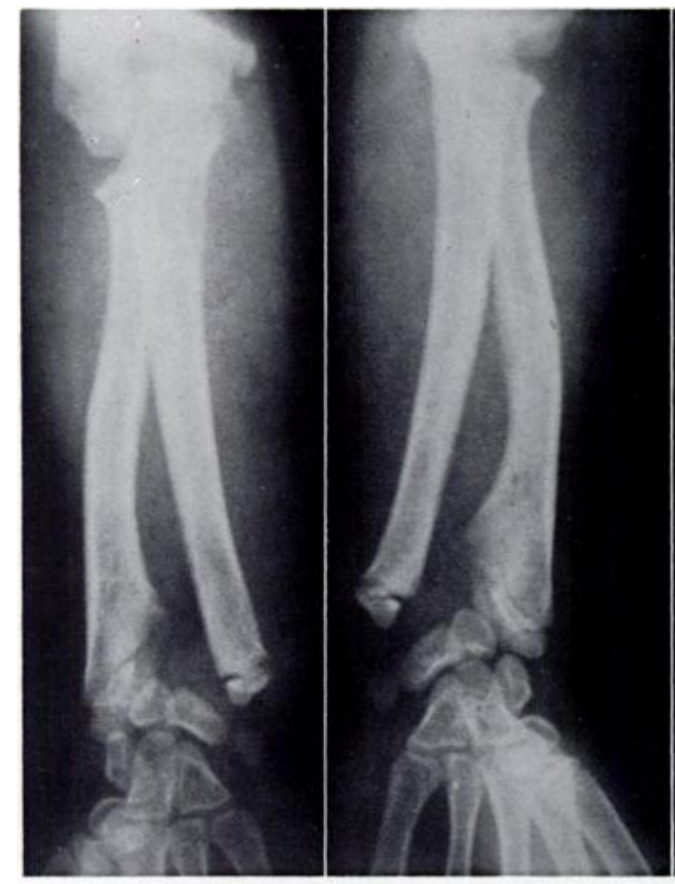

FIG. 2

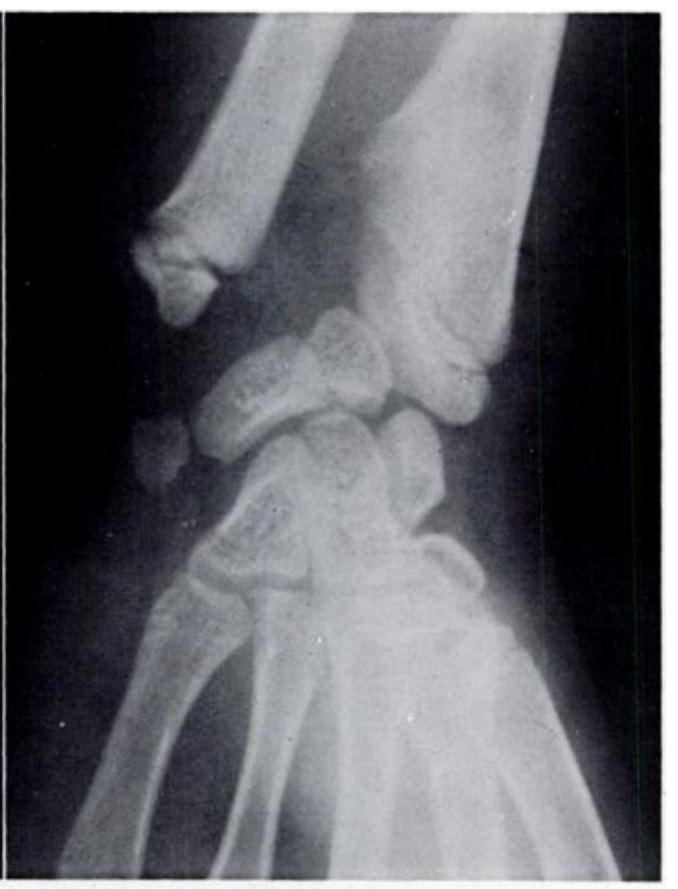

FiG. 3

Figure 2-Radiographs showing the characteristic deformity of forearm and wrist. Figure 3-Detail radiograph showing the wrist deformity.

a standard technique at a distance of two metres. From these radiographs the humerus, radius and ulna in the upper extremity and the femur, tibia and fibula in the lower extremity were measured to determine if mesomelia was present. (Mesomelia is defined as a significant reduction of the ratio of the lengths of the radius and the humerus, which varies from 72 to 75 per cent according to the age and size of the patient, combined with a significant reduction of the ratio of tibial length to femoral length, which normally lies between 83 and 85 per cent.)

\section{RESULTS}

There were twenty-six cases of primary Madelung's deformity of the wrist and one case of dyschondrosteosis. It was possible to obtain a satisfactory study of only seven of the families of patients with primary Madelung's deformity. The others could not be traced. Nevertheless this was compensated for, to some extent, by the size of the families investigated. Thus we were able to examine twenty-four relatives of the index patient in Case $\mathbf{N}$. $\mathbf{H}$. chondrosteosis. We also conclude that it does not occur in the male.

\section{DISCUSSION}

Madelung's disease of the wrist is a primary deformity, distinct from that other disorder described by Madelung in which there are multiple lipomata of the upper back, shoulders and neck (Burrows 1937). A similar deformity of the wrist may also be secondary to other conditions including injury or disease of the growth plate, chromosomal abnormalities as in Turner's syndrome, multiple exostoses, the nail-patella syndrome, neuropathy and dyschondrosteosis.

Dyschondrosteosis, which is the main form of mesomelic dwarfism, was described in 1929, but remarkably few families with the condition have been recorded in the literature. In the family of our index patient (Fig. 6) there are eight other affected members, three of whom are male. This should be contrasted with our twenty-six cases of primary Madelung's disease of the wrist, all of which were female. We consider that most of the male 


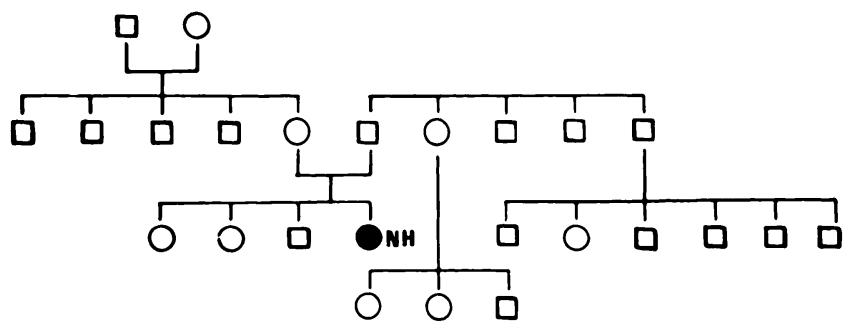

O Normal Female

$\square$ Normal Male

Fig. 4

Family tree of patient N. H. with Madelung's disease.

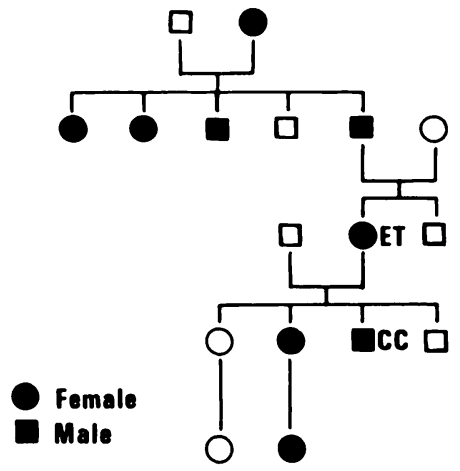

Fig. 6

Family tree of patient C. C. with dyschondrosteosis.

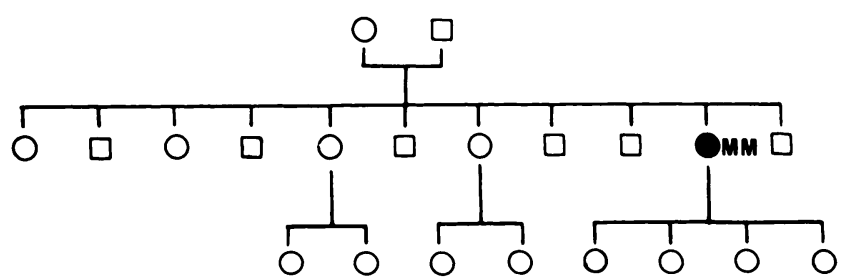

O Normal Female

$\square$ Normal Male

Fig. 5

Family tree of patient M. M. with Madelung's disease.

patients collected by Anton, Reitz and Spiegel were suffering from dyschondrosteosis and a few from secondary Madelung's deformity.

Dyschondrosteosis is thought to be an autosomal dominant (Henry and Thornburn 1967; Boni et al. 1970), but this will not be proved until a case in which the condition is inherited from male to male has been seen. Kaplan (1951) described the first family with this condition, and two of the five members involved were father and son. They were not examined and only a presumptive diagnosis could be made. The affected son of our index patient $E$. T. is now sixteen years of age and an active jockey. It is hoped that it will be possible to know in the next few years whether he fathers the decisive affected male child who would finally prove the pattern of inheritance.

We wish to acknowledge the help of Miss Elizabeth Sawicks and of Mr Michael Morgan, who carried out most of the follow-up studies on these patients.

\section{REFERENCES}

Anton, J. I., Reitz, G. B., and Spiegel, M. B. (1938) Madelung's deformity. Annals of Surgery, 108, 411-439.

Boni, M., Ceciliani, L., Ghisellini, F., and Lenzi, L. (1970) Le condro-osteodisplasie genotipiche. I. Generalità, eziopatiogenesi, classificazione, clinica. Relazione, LV Congresso della Societa Italiana di Ortopedia e Traumatologia, Napoli, October 1970.

Burrows, H. J. (1937) An operation for the correction of Madelung's deformity, and similar conditions. Proceedings of the Royal Society of Medicine, 30, 565-572.

Dannenberg, M., Anton, J. I., and Spiegel, M. B. (1939) Madelung's deformity. consideration of its roentgenological diagnostic criteria. American Journal of Roentgenology and Radium Therapy, 42, 671-676.

Felman, A. H., and Kirkpatrick, J. A., Jun. (1969) Madelung's deformity, observations in 17 patients. Radiology, 93, $1037-1042$.

Henry, A., and Thornburn, M. J. (1967) Madelung's deformity. Journal of Bone and Joint Surgery, 49-B, 66-73.

Herdman, R. C., Langer, L. O., and Good, R. A. (1966) Dyschondrosteosis; the most common cause of Madelung's deformity. Journal of Paediatrics, 68, 432-441.

Kaplan, M., Guy, E., and Cantagrel, A. (1951) Dyschondrostéose familiale. La Presse Médicale, 59, 1723-1725.

Lamy, M., and Maroteaux, P. (1961) Les Chondrodystrophies Genotypiques. Paris: l'Expansion Scientifique Francais, pp. 33-39.

Léri, A., and Weill, J. (1929) Une affection congénitale et symétrique du développment osseux: la dyschondrosteose. Bulletins et Mémoires de la Société des Hopitaux de Paris, 1491-1494.

Madelung, O. W. (1878) Die spontane Subluxation der Hand nach vorne. Verhandlungen der Deutschen Gesellschaft für Chirurgie, 7, $259-276$. 